\title{
Metastatic Basal Cell Carcinoma: A Case Report
}

\author{
Edward Taylor ${ }^{\mathrm{a}, \mathrm{c}}$, Jamie Evans ${ }^{\mathrm{b}}$
}

\begin{abstract}
An 86 year old lady presented to her GP with a 2 month history of right hip and left thigh pain. Pelvic plain x-rays revealed a lytic lesion in the left femur and right acetabulum. Thorough clinical examination found an $80 \times 60 \mathrm{~mm}$ exophytic tumor with an ulcerated surface on her left shoulder. This had been present for over 4 years, the patient believing it 'just a patch of eczema'. A subsequent CT chest, abdomen and pelvis revealed further bony lesions in her sternum, first rib and sacrum. A biopsy of the left shoulder lesion confirmed ulcerated basal cell carcinama (BCC). Hisological and immunohistochemical examination of a biopsy from the bony lesion in the sternum and first rib confirmed a diagnosis of metastaic BCC. Our patient commenced on treatment with imiquimod cream to the primary BCC, had a rod inserted into her left femur in order to prevent a pathological fracture and was offered palliative radiotherapy for the metastatic deposits, which she declined. She died six weeks later. Worldwide BCC incidence is increasing, but has very high cure rates with early complete surgical excision. Metastatic BCC is very rare but incidence is higher with larger tumors, because large vessel blood supply may facilitate haematological seeding of the tumor. Once it metastasises, BCC is highly malignant with short survival times, usually measurable in months. Our patient is likely to have had metastatic disease for some months prior to presentation.
\end{abstract}

Keywords: Carcinoma; Basal Cell; Metastatic; Secondary; Neoplasm

\section{Introduction}

The worldwide incidence of basal cell carcinoma (BCC) is

\footnotetext{
Manuscript accepted for publication June 12, 2012

${ }^{a}$ GP Speciality Trainee, Torbay Hospital, Torbay, United Kingdom ${ }^{\mathrm{b}}$ Consultant Radiation Oncologist, Wellington Hospital, New Zealand

'Corresponding author: Edward Taylor, "Woodlands", Sydenham

Wood, Lewdown, Devon. EX20 4PP. United Kingdom.

Email: edtaylor@doctors.org.uk
}

doi: http://dx.doi.org/10.4021/jmc746w increasing [1], but patients can see very high cure rates with early complete surgical excision. Metastatic BCC is rare, affecting $0.028-0.5 \%$ of the population $[2,3]$. Once it metastasises BCC is highly malignant with short survival times, usually measurable in months. We present a case of $\mathrm{BCC}$ on the shoulder that metastasised to bone.

\section{Case Report}

An 86 year old housewife presented to her GP complaining of right hip and left thigh pain for 2 months. She reported weight loss of $2 \mathrm{~kg}$ over the last 6 months. She had a past medical history of a thyroidectomy for a multinodular goitre in the 1940's, rheumatoid arthritis and hypertension.

Her GP arranged a plain radiograph of her pelvis which demonstrated a lytic lesion in the left femur and right acetabulum (Fig. 1). He referred her urgently to the orthopaedic outpatient clinic.

On examination she was comfortable, but cachectic and pale. An $80 \times 60 \mathrm{~mm}$ exophytic tumor with an ulcerated, haemorrhagic surface was found on her left shoulder (Fig. 2) with left sided axillary lymphadenopathy. On further questioning she admitted to having noticed what she thought to be a 'patch of eczema' on her left shoulder for the last 4 years, which had ulcerated over the last 18 months. She did

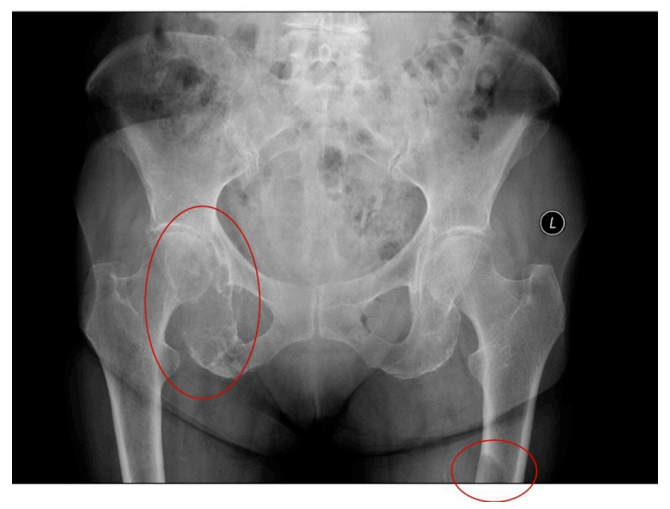

Figure 1. Pelvic $x$-ray demonstrating a lytic lesion in the right acetabulum and left femoral shaft. 


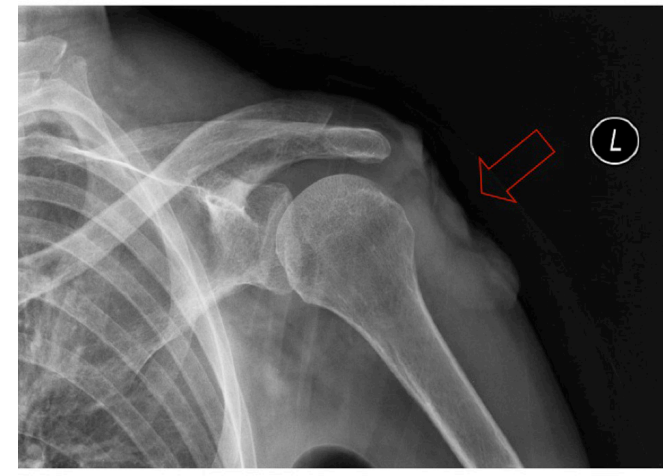

Figure 2. Left shoulder xray demonstrating the ulcerated tumor.

not want to be a bother to her doctor and so had been dressing the ulcerated tumor herself.

She was admitted for further investigation.

Her myeloma screen was negative. A CT chest, abdomen and pelvis revealed bony lesions in her sternum, first rib, sacrum, right acetabulum and left shaft of femur (as seen on her initial x-ray, Fig. 1).

Hisological examination of a biopsy from the left shoulder lesion confirmed an ulcerated BCC (Fig. 3) and biopsies of the bony lesions in the sternum and first rib were provisionally reported as "either BCC with squamoid differentiation or basaloid SCC" (Fig. 4).

The tumor was CK5 positive, consistent with a BCC or a squamous cell carcinoma: the positive BerEP4 was consistent with a BCC of skin, however, a basaloid SCC of endodermal origin (namely, oropharyanx, oesophagus, lung or anal canal) would also show this immunohistochemical profile, but in this case the clinical examination eliminated this possibility. Therefore a diagnosis was made of metastatic basal cell carcinoma.

Our patient commenced on treatment with imiquimod cream to the primary $\mathrm{BCC}$, had uneventful rodding to her left femur in order to prevent a pathological fracture and was

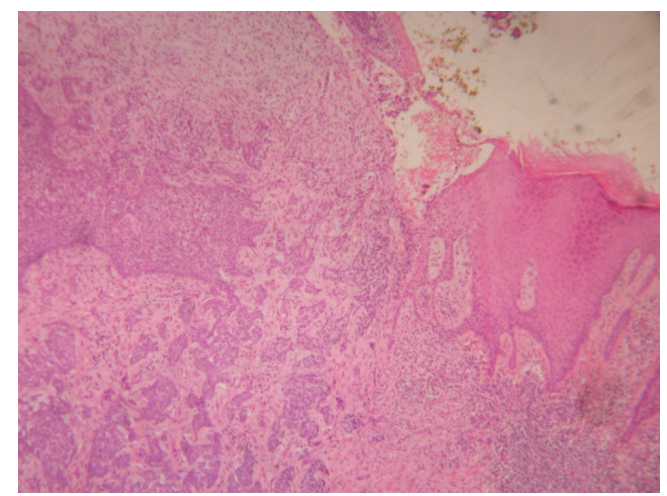

Figure 3. A photomicrograph of the primary BCC on the left shoulder.

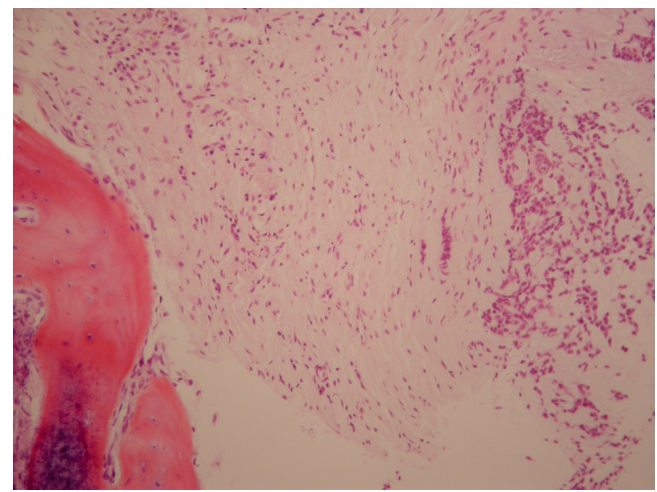

Figure 4. A photomicrograph of the $\mathrm{BCC}$ in the bone marrow.

offered palliative radiotherapy for the metastatic deposits, which she declined. She died six weeks later.

\section{Discussion}

$\mathrm{BCC}$ is a common skin cancer and is showing a worldwide increase in incidence by up to $10 \%$ per year [1]. Thankfully, the incidence of metastatic basal cell carcinoma is rare, affecting just $0.028-0.5 \%$ of the population $[2,3]$.

One of the predictors of aggressive behaviour is a large primary, as large blood vessel supply may facilitate seeding of the tumor via the haematological route [3]. BCC's of the face and scalp are thought to have a greater tendency to metastasise because of the increased concentration of large-calibre vessels [4].The incidence of metastatic spread has been reported as $2 \%$ in BCC's with a diameter larger than $3 \mathrm{~cm}$, $25 \%$ for diameters larger than $5 \mathrm{~cm}$ and $50 \%$ for tumors with a diameter larger than $10 \mathrm{~cm} \mathrm{[4].} \mathrm{The} \mathrm{most} \mathrm{common} \mathrm{sites}$ of metastasis are the regional lymph nodes, followed by the lungs and bones [4-6]. Metastatic spread to skin, liver, and pleura has also been observed, but is less common [7].

Once it metastasises, BCC is highly malignant with a median survival of 8 months $[6,8]$. The 5 -year survival is estimated at $12 \%$ [9]. It is not possible to tell how long our patient had had metastatic disease, though judging by the sizes of the deposits, it is likely they had been present for several months.

Our patient lived to a respectable age despite her metastatic cancer, but had she presented when her BCC was just 'a patch of eczema' the outcome may have been different. Early complete surgical excision of BCC has 5-year disease specific survival rates of more than $99 \%$ for primary tumors not involving the head [10].

\section{Acknowledgement}

Photomicrographs courtesy of: Dr Cynric Temple-Camp 
(Consultant Histopathologist, MedLab Central, New Zealand).

\section{Conflicts of Interest}

Authors declare no conflict of interest.

\section{References}

1. Wong CS, Strange RC, Lear JT. Basal cell carcinoma. BMJ. 2003;327(7418):794-798.

2. Leffell DJ, Carucci JA. Management of skin cancer. In: DeVita VT, Hellman S, Rosenberg ST, editors. Cancer, principles and practice of oncology. 6th ed. Philadelphia: Lippincott Williams\&Wilkins; 2001. p19762002.

3. Robinson JK, Dahiya M. Basal cell carcinoma with pulmonary and lymph node metastasis causing death. Arch Dermatol. 2003;139(5):643-648.
4. Snow SN, Sahl W, Lo JS, Mohs FE, Warner T, Dekkinga JA, Feyzi J. Metastatic basal cell carcinoma. Report of five cases. Cancer. 1994;73(2):328-335.

5. Berlin JM, Warner MR, Bailin PL. Metastatic basal cell carcinoma presenting as unilateral axillary lymphadenopathy: report of a case and review of the literature. Dermatol Surg. 2002;28(11):1082-1084.

6. von Domarus H, Stevens PJ. Metastatic basal cell carcinoma. Report of five cases and review of 170 cases in the literature. J Am Acad Dermatol. 1984;10(6):10431060.

7. Tung R, Vidimos A. Nonmelamona skin cancer. Jan 2009. Accessed 22 February 2012 [http://www.clevelandclinicmeded.com/medicalpubs/diseasemanagement/dermatology/nonmelanoma-skin-cancer].

9. Ozbek N, Meydan D, Guneren E, Cakir S, Kandemr B. Metastatic basal cell carcinoma. N Z Med J. 2004;117(1193):U874.

10. Akinci M, Aslan S, Markoc F, Cetin B, Cetin A. Metastatic basal cell carcinoma. Acta Chir Belg. 2008;108(2):269-272. 